\title{
Entre quatro paredes: atendimento fonoaudiológico a crianças e adolescentes vítimas de violência
}

\author{
Speech-language therapy for abused \\ and neglected child
}

M ilica Satake N oguchi 1

Simone Gonçalves de Assis 1

Nilton Cesar dos Santos 1

\footnotetext{
1 Escola Nacional de Saúde Pública e Centro LatinoAmericano de Estudos deViolência e Saúde Jorge Careli - Claves/Fiocruz. Av. Brasil 4.036/700, Manguinhos, 21040-361, Rio de Janeiro RJ. milica@attglobal.net
}

\begin{abstract}
The objective of this work was to appraise the knowledge and experience of Rio de Janeiro's speech-language pathologist and audiologist about child abuse and neglect. We sent a survey form by mail to a sample of professionals registered at the Speech-Language Pathologist and Audiologist Local Council. The forms were sent twice to each professional. Five hundred forms were sent and 224 professionals responded, of which $71 \%$ worked in private clinics. Among these professionals, $25.8 \%$ had had child clients who suffered some type of abuse. Only $12.9 \%$ of interviewees worked in public health services and almost half of them (43.8\%) had cared of clients who suffered abuse and/or neglect. Even though $88.9 \%$ of respondents who had treated abused children claimed that they would report abuse cases to the Conselho Tutelar, the Brazilian child protective service agency, but only four actually reported. These results suggest that, on the top of the lack of information about the subject, the fact that most speech-language pathologists usually work in private clinics make it difficult for them to report abuses cases to the authorities, as they do not have institutional support.
\end{abstract}

Key words Speech-language pathology, Child abuse, Children, Adolescents
Resumo Buscou-se levantar o conhecimento ea experiência de fonoaudiólogos da cidade do Rio de Janeiro sobre o problema da violência familiar contra a criança e 0 adolescente. Foi efetuado um survey via correio, com duplo envio de questionários, a uma amostra de profissionais registrados no Conselho Regional de Fonoaudiologia. Foram enviados 500 questionários sendo obtidas 224 respostas. Os resultados indicam que, dos $71 \%$ dos entrevistados que trabalham em consultório ou clínica particular, 25,8\% já tiveram clientes infanto-juvenis que sofreram violência familiar. A pesar de somente $12,9 \%$ dos fonoaudiólogos trabalharem em centro/posto de saúde, quase a metade desses profissionais já atendeu vítimas de violência familiar (48,3\%). D os fonoaudiólogos que atenderam pelo menos um caso de violência, $88,9 \%$ indicaram o Conselho Tutelar para encaminhamento dos casos, mas somente quatro fonoaudiólogos afirmaram ter efetuado a notificação. 0 s resultados sugerem que, além da falta de informação sobre o tema, a configuração do trabalho deste profissional, em que predomina a atuação em consultórios particulares, dificulta a realização da notificação, já que não contam com um apoio institucional no enfrentamento deste grave problema.

Palavras-chave Fonoaudiologia, Violência familiar, Crianças, Adolescentes 


\section{Introdução}

A partir do Estatuto da Criança e do Adolescente (Brasil, 1990; artigo 13), o profissional da saúde passou a ter o dever de notificar ao Conselho Tutelar os casos de violência familiar contra a criança e 0 adolescente, suspeitos ou confirmados.

Segundo o último manual do M inistério da Saúde sobre maus-tratos dirigido aos profissionais da saúde (Brasil, 2002), notificar significa iniciar um processo cujo objetivo principal é o de interromper a violência no âmbito da família. Esta notificação, no entanto, não é e nem vale como denúncia policial. Ela indica que o profissional da saúde está dizendo ao Conselho Tutelar: esta criança ou este adolescente e sua família precisam de ajuda! Este manual ressalta o dever do profissional em prover assistência e realizar a notificação, já que esta não é um favor, nem um ato de caridade que o profissional poderá ou não prestar, a seu bel-prazer (...) é um direito que a criança e 0 adolescente têm.

A notificação não deve ser vista como o cumprimento de uma obrigação que tem fim em si mesma. É necessário que o profissional da saúde acompanhe o trabalho do Conselho Tutelar construindo uma parceria que permita compartilhar a decisão tomada para o melhor encaminhamento dos casos atendidos.

Apesar das exigências éticas e legais que este problema apresenta ao profissional da saúde, o número de notificações dos casos de maus-tratos contra crianças e adolescentes é ainda muito pequeno.

Segundo dados da Assessoria de Prevenção de Acidentes e Violência/APAV da Secretaria Estadual de Saúde do Rio de Janeiro (SES-RJ, 2004), no período de julho de 1999 a julho de 2002 foram realizadas 3.628 notificações, sendo que os profissionais que mais notificaram foram: médico (1.441), assistente social (1.415), enfermeiro (64), psicólogo (63), multiprofissional (570) e outros (75). No cadastro desteórgão consta somente uma notificação realizada por fonoaudiólogo.

Acredita-se haver uma subnotificação significativa dos casos de maus-tratos no Brasil. Nos Estados Unidos, somente no ano de 2002, 896 mil crianças foram consideradas vítimas de abuso ou negligência, segundo dados do National Child Abuse and Neglect Data System (National Clearing on Child Abuse and N eglect Information, 2004). No total, $56,5 \%$ dos casos registrados foram encaminhados por profissio- nais, especialmente da área da educação $(16,1 \%)$, representantes da lei $(15,7 \%)$ e serviço social ( $12,6 \%)$. O utros $43,5 \%$ foram realizados por não-profissionais, tais como parentes, vizinhos e amigos. Como se pode observar, diferentemente do que ocorre no Brasil, os profissionais da área da educação parecem estar mais sensibilizados quanto ao problema dos maus-tratos do que os da área da saúde. Segundo este banco de dados, nos últimos cinco anos observou-se uma tendência de aumento de casos provenientes de profissionais e uma diminuição dos não-profissionais.

Autores como Silva (2001a), Deslandes (1999) e Almeida (1998) levantaram as principais dificuldades encontradas pelos profissionais de saúde em relação à notificação. Segundo estes autores, os principais fatores são: 1 ) falta de preparo do profissional para identificar e lidar com os casos de maus-tratos; 2) medo do profissional em fazer a notificação e ter problemas com a justiça ou sofrer retaliações por parte do agressor; 3) falta de suporte para realizar um atendimento mais aprofundado em função da enorme demanda; 4) tradição de uma prática que se restringe ao atendimento das patologias, sem questionar as causas; 5) descrença no poder público e na real possibilidade de intervenção nestes casos; 6) visão de que se trata de um "problema de família", não sendo de responsabilidade de uma "instituição de saúde"; 7) temor de estar enganado enotificar uma "suspeita infundada".

Estas dificuldades encontradas pel os profissionais da saúde vêm sendo enfrentadas com investimento no seu preparo, com a disseminação de manuais, folhetos e cursos voltados principalmente para profissionais da rede pública. Esta capacitação envolve a compreensão do significado, das manifestações e das conseqüências dos maus- tratos para o crescimento e desenvolvimento das crianças e dos adolescentes, além do treinamento para o diagnóstico, a notificação e os encaminhamentos dos problemas (Brasil, 2002). Enfatiza-se não apenas a informação e o conhecimento sobre a temática, mas também a importância de se desenvolver uma consciência social.

O trabalho de Deslandes (1999) aponta para uma outra direção no que se refere ao enfrentamento da dificuldade de notificação pelos profissionais da saúde: a importância de se criar uma dinâmica de responsabilidade institucional para a notificação dos casos. Se, por um lado, tal notificação é de responsabilidade 
do profissional, por outro, é a instituição que deve garantir esta conduta profissional, protegendo o indivíduo de "arcar" com todas as pressões, compartilhando a responsabilidade pelo caso. A autora afirma ainda que é preciso criar uma rotina institucional para a notificação, identificando-se etapas e atribuições dos diferentes atores.

Se existem avanços significativos no setor da saúde como um todo, na fonoaudiologia este tema tem sido pouco debatido. A relevância deste problema para o fonoaudiólogo deve se principalmente ao fato de ele trabalhar com uma população considerada de "alto risco" para sofrer maus-tratos - aquela portadora de alguma deficiência, de má-formação e anomalias congênitas ou genéticas (Sullivan et al., 1991; Deslandes, 1994). Os estudos de H ammond et al. (1989) e Sullivan et al. (1991) indicam que as crianças e adolescentes com dificuldades de comunicação têm uma suscetibilidade maior de serem vítimas de abuso e/ou negligência em função das barreiras comunicativas, da frustração das pessoas que cuidam destas e da interação que tende a ser mais física do que verbal. Os primeiros autores também consideram que 0 abuso e/ou negligência pode privar a criança da estimulação vital necessária para o desenvolvimento da linguagem, resultando em atrasos no seu desenvolvimento.

É importante ressaltar que o abuso/negligência pode ocorrer na própria residência da vítima, mas também em instituições especializadas, no caso de crianças portadoras de alguma deficiência que residem ou permanecem por longos períodos nestes locais.

Segundo Noguchi \& Assis (2003), a conscientização deste profissional no que se refere aos maus-tratos infantis torna-se ainda mais importante se considerarmos as peculiaridades que caracterizam a relação entre este profissional e seus clientes: 1) o contato freqüente e regular com a criança; 2) um período longo de permanência somente com a criança ou o adolescente (sem a presença dos pais ou responsáveis); 3) o conhecimento do cotidiano da criança; 4) a observação e manuseio corporal em certos casos; 5) uma estreita relação com a família.

Os freqüentes contatos que o fonoaudiólogo estabelece com a família no decorrer de todo o processo de intervenção podem ajudar na identificação dos casos e ser uma oportunidade de compreender a dinâmica familiar em que a questão da violência pode estar presente. Este estreito convívio do fonoaudiólogo com a fa- mília proporciona, muitas vezes, um espaço de escuta onde questões relativas à dinâmica familiar são expostas. Com muita freqüência, por acompanhar ativamente a vida de seus pacientes, este profissional torna-se uma importante referência de apoio e confiança da família (Noguchi \& Assis, 2003).

Em função dessas características, as autoras afirmam que a relação entre o fonoaudiólogo, 0 paciente e sua família se amplia mais do que a de outros profissionais da saúde (como médicos, enfermeiros, dentistas, fisioterapeutas e mesmo psicólogos), fazendo com que a clínica fonoaudiológica seja um espaço propício para a identificação e o manejo dos casos de violência.

No entanto, apesar destas especificidades, 0 problema da violência contra a criança e o adolescente tem sido pouco debatido na área com raríssimas publicações. Este estudo portanto, procura trazer à luz o problema da violência na fonoaudiologia abordando o conhecimento, as experiências, as condutas e as dificuldades deste profissional e procurando encontrar vias explicativas para que estas últimas possam ser superadas.

\section{Métodos}

Foi realizado um survey anônimo através do envio de questionários auto-administráveis por correio (Babbie, 1999), acompanhados por uma carta de explicação e um envelope de retorno já selado. 0 Conselho Regional de Fonoaudiologia - 1a Região ofereceu sua mala direta com o nome e endereço de todos os fonoaudiólogos do município do Rio de Janeiro.

0 planejamento amostral considerou a população de 3.113 fonoaudiólogos do município do Rio de Janeiro cadastrados no CRFa1a Região. A amostragem foi definida admitindo-se um erro de estimativa de $4 \%$ e um risco associado a este erro de $5 \%$, totalizando um tamanho amostral de 500 indivíduos (Cochran, 1965). Esse total de questionários foi enviado e 145 retornaram no prazo de dois meses. Foi efetuado um segundo envio, recebendo mais 79 questionários nos dois meses seguintes. No total, retornaram 224 questionários respondidos, constatando-se uma perda de 55,2\%. Tentando conhecer o perfil dos fonoaudiólogos que não haviam respondido aos questionários, procurou-se local izar uma amostra via telefone. Para tanto, a pesquisadora permaneceu vários dias no CRFa-1a Região, que disponibi- 
lizou um funcionário para fazer as ligações telefônicas e solicitar autorização do fonoaudiólogo, visando à não-identificação dos profissionais na pesquisa. Apenas oito entrevistas com fonoaudiólogos que não devolveram 0 questionário (selecionados al eatoriamente na amostra) foram realizadas por telefone e os resultados estão comentados na discussão dos resultados.

O questionário está composto com as seguintes variáveis: tempo de formado; local de trabal ho; conhecimento acerca dos órgãos de notificação; atendimento ou não a crianças e adolescentes vítimas de violência familiar; conduta tomada nesses casos; acompanhamento e desfecho do caso. Algumas poucas questões ficaram em aberto, permitindo ao fonoaudiólogo redigir suas opiniões e condutas.

Foram realizadas análises bivariadas para as variáveis quantitativas. Utilizou-se o teste do qui-quadrado para aferir significâncias.

O estudo foi aprovado pelo Comitê de Ética em Pesquisa da Escola Nacional de Saúde Pública/Fiocruz.

\section{Resultados}

Dos 224 fonoaudiólogos que responderam aos questionários, $24,1 \%$ dos entrevistados (54) atenderam pelo menos um caso em que a criança ou adolescente foi vítima de maus-tratos. A maioria informou nunca ter atendido esses casos $(75,9 \%)$.

A tabela 1 indica o local de trabalho dos fonoaudiólogos que responderam à pesquisa, assim como o percentual dos que já atenderam a crianças e adolescentes vítimas de violência, segundo o tipo de vínculo profissional que possuem. O bservou-se que a maioria dos entrevistados trabalha em consultório ou clínica particular (71\%). Desses profissionais com emprego privado, 25,8\% já tiveram clientes infanto-juvenis que sofreram violência familiar.

A inserção profissional em escolas foi a segunda forma mais freqüente, seguida pelo trabalho em hospital/maternidade e empresas/indústrias. Deve-se destacar que, embora apenas $12,9 \%$ dos fonoaudiólogos informaram trabalhar em centro/posto de saúde, quase a metade desses profissionais já atendeu vítimas de violência familiar, diferenciando-se de todos os demais tipos de inserção profissional pela maior proximidade com pacientes em situação de maus-tratos $(48,3 \% ; p<0,01)$.
Não foi constatada nenhuma diferença quanto a atender ou não crianças e adolescentes vítimas de violência familiar em relação ao tempo de formação. Verificou-se que $25,5 \%$ dos fonoaudiólogos que responderam ao questionário tinham até 5 anos de formados, 22,7\% entre 6 e 10 anos e $51,8 \%$ mais de 10 anos de formatura. Vale apontar que $17,9 \%$ dos profissionais com até 5 anos de formados já haviam atendido casos de violência familiar, percentual que se eleva para $32 \%$ entre os formados entre 6 e 10 anos e decai novamente para $23,7 \%$ entre os com mais de 10 anos de vida profissional.

Sobre as instâncias que deveriam ser procuradas no caso de maus-tratos, $90,2 \%$ dos fonoaudiólogos reconheceram a Vara da Infância e Juventude como a principal instituição a ser acionada em casos de violência familiar. Em segundo lugar, $73 \%$ informaram que procurariam o Conselho Tutelar. Dentre os respondentes que afirmaram ter atendido pelo menos um caso de violência familiar, a porcentagem daqueles que procurariam o Conselho Tutelar sobe para 88,9\% (Tabela 2), sinalizando possuírem melhor conhecimento do órgão mais indicado para apoiar esses casos.

Cabe ressaltar que $51,8 \%$ reconheceram a polícia como órgão a ser buscado em caso de violência familiar. Por outro lado, poucos lembraram dos Conselhos Municipais de D efesa e M inistério Público, órgãos mais implicados na defesa dos direitos da criança e do adolescente.

A conduta mais citada pelos fonoaudiólogos que atenderam algum caso de violência familiar foi o contato com a família, mencionado por 34 fonoaudiólogos. Este contato consistiu em "conversas com a família" (que pode ser com a mãe, os pais, os responsáveis ou o agressor), questionamento com relação ao episódio da violência, ameaças para que o episódio não se repita, conversas procurando confirmar ou não a veracidade dos fatos e orientações à família. A penas quatro fonoaudiólogos afirmaram ter procurado o Consel ho Tutelar; dois, o Juizado e quatro informaram ter encaminhado para "órgãos públicos" sem especificar quais.

Quanto ao acompanhamento e desfecho dos casos relatados nos questionários, a maioria dos fonoaudiólogos informou continuar atendendo os casos de crianças/adolescentes vítimas de violência ( $59 \%$ ). Este resultado deve ser visto com cautela, considerando que, destes que afirmaram continuar acompanhando, $26 \%$ citaram outros casos nos quais ocorreu o aban- 
Tabela 1

Atendimento fonoaudiológico a crianças e adolescentes vítimas de violência familiar segundo o local de trabalho do profissional.

\begin{tabular}{lcccc}
\hline Local de trabalho & \multicolumn{2}{c}{$\begin{array}{c}\text { Total com vínculo } \\
\text { de trabalho } \mathbf{( N = 2 4 4 )}\end{array}$} & $\begin{array}{c}\text { Atendimento à vítimas } \\
\text { de violência (N=54) }\end{array}$ \\
\hline Consultório/clínica particular & $\mathbf{N}$ & $\%$ & $\mathbf{N}$ & $\%$ \\
Escolas/creches & 159 & 71,0 & 41 & 25,8 \\
H ospital/maternidade & 46 & 20,5 & 15 & 32,6 \\
Empresas/indústrias & 38 & 17,0 & 12 & 31,6 \\
Faculdades/universidade & 31 & 13,8 & 10 & 32,3 \\
Centro/posto de saúdel & 31 & 13,8 & 7 & 22,6 \\
Rádio/televisão/teatro & 29 & 12,9 & 14 & 48,3 \\
\hline
\end{tabular}

$1 p<0,01$

Tabela 2

Órgãos que ajudariam/deveriam ser informados no caso de suspeita ou confirmação de violência familiar contra criança/adolescente.

\begin{tabular}{|c|c|c|c|c|c|c|}
\hline \multirow{3}{*}{$\begin{array}{l}\text { Ó rgão mencionado em caso } \\
\text { de violência familiar }\end{array}$} & \multicolumn{6}{|c|}{ Atendimento a vítima de violência familiar } \\
\hline & \multicolumn{2}{|c|}{ Sim $=54$} & \multicolumn{2}{|c|}{ Não $=170$} & \multicolumn{2}{|c|}{ Total = 224} \\
\hline & $\mathbf{N}$ & $\%$ & $\mathbf{N}$ & $\%$ & $\mathbf{N}$ & $\%$ \\
\hline Vara da Infância e da Juventude & 51 & 94,4 & 151 & 88,8 & 116 & 90,2 \\
\hline Conselho Tutelar1 & 48 & 88,9 & 116 & 68,2 & 164 & 73,2 \\
\hline Polícia & 26 & 48,1 & 90 & 52,9 & 46 & 51,8 \\
\hline Conselhos M unicipais de Defesa & 18 & 33,3 & 39 & 22,9 & 202 & 25,4 \\
\hline M inistério Público & 14 & 25,9 & 32 & 18,8 & 57 & 20,5 \\
\hline
\end{tabular}

$1 p<0,01$

dono do tratamento fonoaudiológico e $19 \%$ entraram em contradição, relatando 0 abandono do tratamento em outras questões.

\section{Discussão dos resultados}

Duas questões merecem ser destacadas diante dos resultados apresentados. A primeira delas refere-se ao encaminhamento dos casos de violência familiar aos órgãos públicos: a Vara da Infância e da Juventude (VIJ) foi mais lembrada pelos entrevistados do que o Conselho Tute$\operatorname{lar}(\mathrm{CT})$.

A atribuição destes órgãos é bastante distinta: os CT basicamente acolhem e averiguam as denúncias. Quando constatada sua veracidade, procuram imediatamente cessar a situação de violência para então aplicar outras medidas que possam restaurar os direitos da criança e do adolescente. É o próprio CT que deveria en- caminhar à VIJ e ao M inistério Público os casos mais complexos em que, por exemplo, é necessária a destituição do pátrio poder. Isto porque o CT é não-jurisdicional, não tendo autoridade para julgar conflitos, o que compete a um juiz. Somente em cidades onde não existe um CT, a VIJ seria a primeira unidade a ser acionada - 0 que não ocorre na cidade do Rio de Janeiro, onde foi realizada a pesquisa.

Nesse sentido, a indicação da VIJ como órgão mais citado pelos entrevistados pode sugerir, ao invés da proteção, uma visão predominante da culpabilização na abordagem do problema dos maus-tratos. Esta visão se encontra na "contramão" dos esforços que o setor da saúde vem tendo, procurando redefinir seu papel diante destes casos.

A segunda questão se refere ao fato de que embora alta porcentagem de profissionais saiba que um caso de maus-tratos deva ser encaminhado ao Conselho Tutelar, um número 
irrisório de notificações foi de fato realizado. Isso parece indicar que a baixa notificação não se deve somente à falta de informação do fonoaudiólogo, já que a maioria sabe para onde encaminhar. A discussão apresentada nos próximos itens visa encontrar vias explicativas que possam ajudar na compreensão deste aparente paradoxo.

É importante salientar que al guns entrevistados que já tinham atendido um caso de violência familiar, preencheram inicialmente 0 questionário afirmando não terem atendido nenhum caso e depois, geralmente nos comentários, relatavam al gum caso. Tal fato sugere que os números apresentados neste trabal ho podem estar subestimados. Esta postura também foi observada no grupo ondefoi realizada a entrevista por telefone. Apesar das respostas deste último grupo não terem sido contempladas nos resultados anteriormente apresentados, vale tecer alguns comentários.

Dos oito entrevistados por telefone, sete já haviam atendido a um caso de violência familiar contra criança/adolescente. Alguns se mostraram pouco à vontade em participar do estudo, temendo que as informações pudessem ser repassadas ao Conselho. Outros negaram a principio, mas no decorrer da entrevista acabaram por relatar sua experiência com al gum caso (um deles justificou que tinha atendido somente um caso e o outro justificou dizendo que se tratava somente de uma suspeita).

A pesar do pequeno número de entrevistas realizadas por telefone, a el evada freqüência de atendimento a crianças/adolescentes vítimas de violência familiar pode sugerir uma maior atuação do fonoaudiólogo do que a constatada através dos questionários. Nesse sentido, talvez, o baixo número de questionários devolvidos pelo correio pode ser indício de uma não-participação deliberada mais do que uma perda aleatória.

0 fato de ter o apoio do CRFa-1a Região para a realização da pesquisa pode também ter contribuído para inibir a participação de alguns fonoaudiólogos, que, temendo possíveis sanções, preferiram omitir tal informação. Em uma das entrevistas telefônicas, o fonoaudiólogo explicitou este temor, perguntando ao pesquisador se o CRF teria acesso às informações do questionário. Apesar de serem informados de que as informações desta pesquisa são sigilosas eque os participantes foram identificados por meio de números, muitos profissionais se sentiram inseguros em dar informações sobre sua experiência com o problema da violência familiar. Talvez o próprio tema da violência familiar, ainda interdito e considerado um problema a ser resolvido entre as "quatro paredes" familiares, contribua para essa baixa resposta observada entre os fonoaudiólogos.

\section{A configuração do local de trabalho do fonoaudiólogo e suas implicações no problema da notificação}

Considerando que a maioria dos entrevistados trabalha em consultório ou clínica particular $(71 \%)$, isto pode significar que estes profissionais não contam com um apoio institucional para lidar com os casos de maus-tratos, 0 que dificulta o processo de notificação. No caso dos fonoaudiólogos que não se inserem em equipes de saúde, realizar a notificação significa enfrentar este processo de forma solitária.

Outro resultado que aponta nesta mesma direção é o que indicou que mais fonoaudiólogos que identificaram e atenderam casos de maus-tratos trabalhavam em unidades públicas de saúde. Constantes ações de sensibilização e capacitação profissional realizadas pelas Secretarias Estadual e M unicipal de Saúde do Rio de Janeiro nos últimos anos podem estar influenciando esta maior capacidade de detecção de casos no serviço público de saúde.

0 fato de o fonoaudiólogo trabalhar em uma clínica com outros profissionais não garante que, no caso de atender uma vítima de maus-tratos, ele possa contar com um segundo integrante da equipe para dividir efetivamente a responsabilidade sobre 0 caso. M uitas vezes estas parcerias se restringem ao encaminhamento de casos, divisão de espaço físico e despesas em geral, não havendo de fato uma integração dos profissionais no atendimento dos casos. $O$ trabalho de M oreira e Friedman (2002) aponta esta não-integração entre o fonoaudiólogo com outros profissionais, ocorrendo apenas uma "justaposição de saberes alheios entre si".

Algumas das dificuldades encontradas pelos fonoaudiólogos no atendimento a vítimas de violência, tema absolutamente ancorado nas ciências sociais, está nas origens da fonoaudiologia no Brasil. 0 trabal ho de Silva e M assi (1999) sobre as origens das práticas fonoaudiológicas em São Paulo pode contribuir na reflexão dos resultados obtidos neste estudo com fonoaudiólogos da cidade do Rio de Janeiro.

Para estas autoras, a origem destas práticas se encontra no processo de escolarização que 
ocorreu no início do século até a década de 1940. 0 pensamento higienista vigente nesse período associava os "males do Brasil" com a composição étnica da população e com a herança colonial (Lima \& Hochman, 2000). A normatização da língua nacional era uma questão fundamental na lógica do discurso higienista propagado por médicos, educadores e outros agentes ligados às instituições governamentais (Silva \& M assi, 1999). As variações dialetais, que eram a principal forma de identificação étnica, deveriam ser alvo no combate aos "estrangeirismos".

Para essas autoras, a escolarização tinha uma tarefa disciplinadora, apagando o passado, as tradições, e a língua convertendo estes grupos em cidadãos da N ova Pátria. Este universo escolar onde se buscava o aperfeiçoamento de estratégias de classificação dos escolares (através da construção de escalas, baterias de testes e provas para medir o cabedal intelectual e lingüístico das crianças) e a normatização dos desvios da língua, fundamentados em conceitos de aquisição e desenvolvimento de linguagem, bem como na definição entre o normal e o patológico, culminou com a oficialização da fonoaudiologia. 0 discurso técnicocientífico que justificava e explicava o controle da linguagem encobria o caráter político-cultural que se encontra nas raízes das práticas fonoaudiológicas.

Para Silva e M assi (1999), quando a língua falada no País estava padronizada a ponto de atender às demandas econômicas e sociais, estas práticas se deslocaram para um contexto clínico.

No final da década de 1950 até meados de 70 , tais práticas se caracterizavam pelo trabaIho de reabilitação ou cura dos distúrbios da linguagem:

[a Fonoaudiologia] distanciou-se das instituições públicas e passou a ser uma profissão voltada a um pequeno grupo da sociedade. (...). É por esta razão que durante meados dos anos $60 \mathrm{e}$ final da década de 70, a atuação fonoaudiológica estava praticamente restrita a uma prática curativa, desenvolvida nos consultórios particulares, em alguns hospitais e em algumas instituições assistencialistas ( grifo nosso). Os trabalhos institucionais ou públicos eram desenvolvidos por pessoas ou grupos isolados, sem maiores recursos (Silva \& M assi, 1999).

Este distanciamento das instituições públicas pode repercutir na questão da notificação, reforçado pelo fraco apoio institucional.

\section{A conduta adotada pelo fonoaudiólogo diante de um caso de maus-tratos - enfrentando o problema sozinho}

Com relação à conduta mais citada pelos respondentes que já atenderam casos de violência familiar, destacam-se 27 relatos de fonoaudiólogos que buscaram averiguar o episódio de violência e outros 7 informaram fornecer orientação familiar. Ainda que estes últimos não tenham entrado no mérito da suspeita ou confirmação da violência, as orientações realizadas se constituíram em um trabalho de intervenção que se mostrou muito eficaz, já que o atendimento não se restringe à vítima, mas inclui toda a família: a partir do momento que valorizamos o usuário e nos aproximamos destas famílias, tentando melhorar a sua auto-estima, a própria família se sente mais confiante (...) não só 0 agredido tem que ser tratado. Quando se trata 0 agressor a história se modifica (fono 3 ).

O Guia do Ministério da Saúde (Brasil, 2001) afirma que o profissional da saúde deve evitar: perguntar se um dos pais foi o responsável pelo ocorrido, insistir em confrontar dados contraditórios ou aferir registros, confrontar os pais com descrições trazidas pela criança ou adolescente ou assumir postura de policial ou detetive. Recomenda que o profissional e a vítima não ajam sozinhos para evitar riscos maiores, devendo, sempre que possível, se inserir em uma rede de serviços especializados. Afirma ainda que a abordagem deve ser multidisciplinar eque énecessário um trabalho conjunto com os Conselhos Tutelares.

Os resultados encontrados sugerem que 0 fonoaudiólogo freqüentemente acaba enfrentando o problema sozinho, apesar de não ser esta a conduta mais adequada. M ais uma vez, estes resultados reafirmam que estes profissionais não contam com um apoio institucional no enfrentamento do problema.

A segunda conduta mais citada pelos entrevistados foi o encaminhamento psicológico e, em seguida, o encaminhamento para o serviço social. Também foram citados os encaminhamentos ao médico, à escola e aos outros profissionais, sem especificar quais. Esta alta ocorrência de encaminhamentos a outros profissionais e um número baixíssimo de notificações ao Conselho Tutelar podem indicar que o fonoaudiólogo prefere encaminhar estes casos de violência a outros profissionais e não diretamente ao Conselho Tutelar, eximindo-se da responsabilidade ética e legal que requer estes casos. 
É evidente que os casos de maus-tratos ne cessitam de um acompanhamento interdisciplinar, mas o fonoaudiólogo deve participar da notificação e acompanhamento dos casos, especialmente porque possui informações importantes sobre a criança/adolescente vitimado e sua família.

Este depoimento mostra uma conduta cuidadosa diante de um caso de violência física: conversei sobre os danos morais/psicológicos que poderia ocorrer futuramente com essa criança, indiquei um psicólogo e comecei a acompanhar mais de perto essa criança. (...) H ouve uma outra incidência, mas sem marcas (corporais), conversei com a mãe (a agressora) elheinformei que se essa atitude perdurasse, ela seria encaminhada ao Conselho Tutelar (fono 103).

D os que atenderam al gum caso de maustratos, o encaminhamento ao Conselho Tutelar foi relatado somente por quatro fonoaudiólogos, sendo que, em todos os casos, os relatos revelam uma experiência negativa: em três casos, a criança continuou sofrendo maus-tratos; e em um caso, houve abandono do tratamento.

Apesar da experiência negativa que muitos profissionais da saúde relatam na sua relação com o Conselho Tutelar, é importante que a notificação seja feita. 0 campo de ação dos profissionais da saúde tem pouco poder de resolução quando comparado aos CT, especialmente nos casos em que é necessário cessar a situação de violência de forma imediata ou naqueles onde é necessário 0 apoio de outros setores públicos como, por exemplo, relacionados à educação, transporte, moradia e trabal ho.

Nesse sentido, a relação dos profissionais da saúde com os CT deveria ser a de parceria, já que ambos podem contribuir de forma diferente e complementar no enfrentamento do problema da violência familiar.

\section{0 desfecho dos casos de maus-tratos atendidos pelos fonoaudiólogos}

Quanto ao desfecho dos casos de maus-tratos, a maioria abandonou o tratamento, como mostram estes depoimentos a seguir: alguns sumiram da clínica quando chamados pela dire ção [da clínica]. Outros desmentiam o caso por medo das conseqüências em casa (fono 50); ou então ocorreu 0 abandono do tratamento da criança porque a família mudou-a de escola, impossibilitando qualquer contato posterior (fono 78).

U ma das possíveis razões para 0 abandono pode ser a conduta inadequada por parte do profissional diante dos casos. Um fonoaudiólogo aponta com precisão este problema: minha falta de informação quanto à melhor conduta neste caso, possivelmente, levou à desi stência do tratamento e frustrou a possi bilidade de al guma intervenção mais eficaz (fono 2).

Nos casos em que houve abandono do tratamento fonoaudiológico e não foram realizadas intervenções com as famílias, pode-se supor que as crianças que passaram pela clínica fonoaudiológica continuam em situação de risco.

Quatro respondentes relataram um desfecho desfavorável em que a criança/adolescente voltou a sofrer violência, a exemplo deste depoimento: 0 caso foi encaminhado para o Juizado, depois o pai [agressor] ganhou a causa e ficou com a criança e ainda expulsou a mãe de casa, a criança desmentiu todo o acontecido para o Juiz. (...) 0 outro responsável fica com medo de denunciar, e acaba sendo conivente com o agressor e a situação de agressão física, emocional ou sexual torna a se repetir infinitas vezes (fono $110)$.

Os casos relatados que tiveram um desfecho favorável apontam para a importância do atendimento multidisciplinar. Alguns depoimentos ilustram a eficácia dessa estratégia: tiveram o acompanhamento da equipe obten do um desfecho bom, em que os pais, sob orientação, deixaram de agredir seus filhos (fono 83); encaminhei-as [agressor e vítima] para a assistente social e psicólogo (...). Felizmente os três casos estão tendo um bom desenvolvimento nas terapias fonoaudiológica e psicológica, além de apresentarem melhora na escola (fono 91); família acompanhada pelo Serviço Social durante a terapia fonoaudiológica e após alta fonoaudiológica. Sucesso no desfecho do caso (fono 214).

\section{Silêncio e sofrimento do profissional da saúde}

Um outro fator que não pode ser esquecido se refere aos sentimentos que este tema desperta no profissional. No caso do fonoaudiólogo e dos profissionais da saúde em geral isto é particularmente importante visto que tais situações se confrontam com a onipotência, o narcisismo e a necessidade de proteção que muitas vezes norteiam a ação deste profissional.

Para Freud (1981), o narcisismo em um certo sentido é o complemento libidinoso del egoísmo del instinto de conservación; egoísmo que atribuimos justificadamente, en cierta medida, a todo ser vivo. 
A sensação de violação do narcisismo que um caso de maus-tratos provoca no profissional da saúde pode ser comparada a outras situações, como, por exemplo, em gestações inviáveis, neonatos com doenças irreversíveis e intratáveis ou pacientes terminais. Nestes casos, 0 profissional da saúde deve ser trabalhado para que possa ser capaz de tolerar o incompleto, 0 diferente.

Nos estudos sobre tanatologia, a experiência pessoal do profissional da saúde é freqüentemente tematizada. Segundo Kovács (1991), negar é uma forma de defesa, de não entrar em contato com as experiências dolorosas. A grande dádiva da negação e da repressão é permitir que se viva num mundo de fantasia. A situação da terminalidade ou mesmo dos maus-tratos pode ser tão ameaçadora para o profissional que sua única possibilidade é a negação.

0 artigo de Torres e Guedes (1987) que discute a questão dos doentes terminais para 0 psicólogo afirma que a negação pode manifestar-se no silêncio ou na omissão diante da questão da morte. No caso de maus-tratos, a negação do profissional da saúde, manifestada especialmente pela omissão, pode ter conseqüências graves para a criança ou adolescente que permanece numa situação de risco.

Estas autoras afirmam ainda que o fato de existirem poucos trabalhos sobre o assunto é também uma forma de negação. Podemos nos indagar diante da escassez maior ainda de trabal hos sobre maus-tratos na área de fonoaudiologia, se esta negação também estaria presente.

A dificuldade em lidar com o outro (o paciente) decorrente da dificuldade do próprio profissional é também apontada no trabalho de Coser Filho (1986) sobre psiquiatria e prática médica: algo age no médico influenciando a relação que ele mantém com o paciente, e que esse algo é de ordem inconsciente, seja ele ligado a sua história pessoal ou as suas crenças ideológicas. (...) parece que é necessário ao médico manter a posição de desconhecimento da realidade psíquica de seus pacientes, afinal, a garantia do desconhecimento de sua própria realidade psíquica, de suas posições fantasmáticas diante de cada paciente. Com isso ele ignora a vida subjetiva de seu paciente e se defronta com ele como se fosse apenas um corpo biológico.

Esta tentativa de recorte, de fragmentação do sujeito pela dificuldade que se impõe a consideração de sua totalidade, pode também nos ajudar a compreender a atuação do profissional da saúde que procura restringir sua ação aos cuidados, reparos e reabilitação de seus clientes.

O depoimento deste fonoaudiólogo é um exemplo claro desta dificuldade. Em resposta à pergunta relativa à conduta diante de um caso de maus-tratos, informa: N enhuma. Eu apenas exerço a profissão (...) em um hospital infantil. Como fono apenas observo (fono 209). 0 depoimento parece esvaziar do papel profissional qualquer possibilidade de intervenção nestes casos.

A tradição corretivo-normatizadora que norteia a prática fonoaudiológica não apenas limita o olhar do profissional às queixas lingüísticas e comunicativas, mas serve de "bode expiatório". É a desculpa ideal para que o profissional se limite a tratar destas queixas, deixando de lado o sofrimento do sujeito, sua família ea violência que se instaura nesta relação.

Outro entrevistado "sai de cena" diante de um problema que parece ser inatingível, insolúvel e, assim, insuportável: ainda somos muito pequenos como seres humanos para podermos intervir nesta triste realidade (fono 60).

É inegável que este tema desperta em muitos profissionais sentimentos intensos, que são muitas vezes difíceis de manejar. No entanto, é necessário que o profissional da saúde não perca de vista seu compromisso terapêutico. Coser Filho (1986) aponta para uma direção possível da relação médico/paciente, mas que pode ser estendida a qualquer profissional da saúde: para compreender o que se passa na relação do médico com seu paciente é preciso que o primeiro ultrapasse a atitude de buscar um responsável, um culpado, aí pode-se estabelecer uma relação de cooperação sem angústia ou culpabilidade excessiva.

Esta preocupação com o profissional da saúde também está presente no manual do M inistério da Saúde (Brasil, 2001), que indica a necessidade de se criarem espaços de discussão que possam dar um respaldo psicológico à equipe.

Dessa forma, procuramos indicar neste item que, como a abordagem dos casos de maustratos é uma tarefa muito pesada do ponto de vista emocional, o profissional da saúde deve trabalhar com seus próprios sentimentos para que possa avaliar com mais clareza seu papel profissional (inclusive ético e legal) diante de cada caso. No entanto, a oportunidade de trabalhar tais questões raramente chega às mãos do fonoaudiólogo e de outros profissionais da saúde que trabalham em consultórios e clínicas particulares. 


\section{Violência estrutural e medo do profissional da saúde}

Um outro aspecto que também deve ser ressaltado neste estudo é a relação destas dificuldades de notificação dos casos de violência familiar com a violência social em geral, isto é, como esta última pode repercutir na atitude dos profissionais que lidam com o problema dos maus-tratos.

Tomemos como exemplo a cidade do Rio de Janeiro, onde as pessoas vivem amedrontadas. 0 fato de morar nesta cidade pode ter al gumas implicações na conduta destes profissionais. Realizar a notificação expõe o profissional, que, no caso daqueles que trabal ham sozinhos, sente-se ainda mais desamparado e desencorajado a enfrentar o problema. É notória a dificuldade dos Conselhos Tutelares em realizar as visitas aos domicílios localizados em áreas dominadas pelo tráfico de drogas (Brasil, 2002). 0 depoimento deste fonoaudiólogo também ilustra o problema: na institui ção que eu trabalhava, alguns casos tiveram um desfecho além de nossos limites - adolescentes estavam envolvidos com tráfico de drogas, sendo que um até foi assassinado (fono 30).

0 temor de represálias que domina fortemente o imaginário coletivo dos profissionais da saúde, no contexto da crescente violência social, toma proporções ainda mais assustadoras desencorajando-os a efetuar a notificação.

\section{Considerações finais}

A partir deste estudo com os fonoaudiólogos da cidade do Rio de Janeiro, podemos concluir que a dificuldade de notificação não parece estar relacionada somente à falta de informação deste profissional. Procuramos apontar neste trabalho diversos fatores que podem dificultar este processo, especialmente sua atuação isolada. O conhecimento das dificuldades pode ajudar na elaboração de estratégias de ação para o enfrentamento deste grave problema.

As considerações realizadas neste presente trabalho partiram de um inquérito realizado com fonoaudiólogos da cidade do Rio de Janeiro, mas podem ser estendidas a outros profissionais da saúde.

0 elevado percentual de perdas dos questionários pode indicar maiores dificuldades dos profissionais em relatar o tema, embora sejam comuns baixos índices de resposta em questionários por correio (Babbie, 1999). Deve-se con- siderar este fato como uma limitação do estudo, que possivelmente pode estar apresentando resultados subestimados.

0 trabalho de conscientização e sensibilização dirigido a estes profissionais que tem sido feito com a difusão de diferentes manuais e informativos é direcionado principalmente àqueles que estão inseridos em "equipes de saúde" ou na rede pública de saúde. Considerando as características da configuração do trabalho do fonoaudiólogo, esteprofissional podenão estar sendo atingido por tais campanhas. As orientações que constam no manual do M inistério da Saúde (Brasil, 2002) reforçam esta idéia: a equipe de saúde compartilhará responsabilidades com o Consel ho Tutelar em cada caso encaminhado. Quando há uma boa relação entre ambas as instituições [CT e os serviços de saúde] (...) ocorrem contatos telefônicos em que os profissionais da saúde e consel hei ros discutem sobre as condutas.

Na própria Ficha de Notificação Compulsória de Casos Suspeitos ou Confirmados de M aus-Tratos/Abuso Sexual contra Crianças e Adolescentes da Secretaria de Estado de Saúde do Rio de Janeiro consta somente o termo "unidade" na identificação do atendimento (Unidade em que foi realizado 0 atendimento, endereço da Unidade, município e profissionais envolvidos no atendimento, sendo necessário a assinatura do responsável pela notificação e a assinatura da Direção da Unidade). 0 fonoaudiólogo que trabalha em consultório e clínicas particulares poderia encontrar certa dificuldade no preenchimento desta ficha.

A necessidade de um apoio institucional no enfrentamento dos maus-tratos infantis parece-nos urgente, já que a maioria dos fonoaudiólogos não conta com uma equipe de trabal ho, estando confinada "entre as quatro paredes" de seu consultório. Mesmo aqueles que trabalham em instituições muitas vezes não conseguem realizar uma condução adequada destes casos, porque não existe uma rotina de atendimento.

A parceria de setores da saúde responsáveis pela difusão da informação com entidades de classe (que são comumente a única referência para o fonoaudiólogo) pode ser uma alternativa viável de se atingir estes profissionais para 0 enfrentamento de um problema social tão arraigado e complexo. Algumas entidades de classe tais como o Conselho Regional de Psicologia-5a Região e a Sociedade de Pediatria do Rio de Janeiro, em parceria com órgãos públicos, têm se mobilizado para enfrentar o problema da violência familiar. 


\section{Colaboradores}

M S Noguchi foi a responsável pela condução da pesquisa e redação do texto; SG Assis, pela redação; e NC Santos, pela análise estatística.

\section{Referências bibliográficas}

Almeida EC 1998. Violência doméstica: um desafio para a formação do pediatra. Dissertação de mestrado, Instituto de M edicina Social da Universidade do Rio de Janeiro.

Babbie E 1999. M étodos de pesquisas de survey. Ed. UFM G, Belo Horizonte.

Brasil 1990. Estatuto da Criança e do Adolescente (ECA). Lei Federal no 8.069 de 13/07/1990. Brasília

Brasil 2001. Violência intrafamiliar: orientações para a prática em serviço. M inistério da Saúde/Secretaria de políticas de Saúde, Brasília. (Série Cadernos de Atenção Básica n. 8)

Brasil 2002. Notificação de maus-tratos contra crianças e adolescentes pel os profissionais da saúde: um passo a mais na cidadania em saúde. M inistério da Saúde/ Secretaria de Assistência à Saúde, Brasília.

Cochran WG 1965. Técnicas de amostragem. Editora Fundo de Cultura, Rio de Janeiro.

Coser Filho O. 1986. Psiquiatria e medicina: contribuição ao estudo dos transtornos psíquicos na prática médica e da formação psicológica do médico. Dissertação de mestrado. Instituto de Psiquiatria/UFRJ, Rio de Janeiro.

Deslandes SF 1999. 0 Atendimento às vítimas de violência na emergência: "prevenção numa hora dessas?". Ciência \& Saúde Coletiva 4(1):81-94.

Deslandes SF 1994. Atenção a crianças e adolescentes vítimas de violência doméstica: análise de um serviço. Cadernos de Saúde Pública 10 (supl.1):177-187.

Freud S 1981. Introducción al narcisismo. In O bras completas - Tomo II. (4a ed.). Biblioteca Nueva, Madri.

Hammond J, Nebel-Gould A \& Brooks I 1989. The value of speech-language assessment in the diagnosis of child abuse. J. Trauma 29(9):1258-1260.

Kovács MJ 1991. Pensando a morte da formação de profissionais da saúde. In RM S Cassorla (org). Da morte. Papirus Editora, Campinas.
Lima NT \& Hochman G 2000. Pouca saúde, muita saúva, os males do Brasil são... Discurso médico-sanitário e interpretação do País. Ciência e Saúde Coletiva 5(2): 331-332.

Moreira DR \& Friedman S 2002. Fonoaudiologia: o sentido que se produz nas áreas médica, odontológica e fonoaudiológica. Pró-fono: Revista de Atualização Científica 14(1):129-136.

National Clearing on Child Abuse and Neglect Information - Administration for children and families - US. Department of Health and Human Services. 2004. Child M altreatment 2002. 12 April 2004. Disponível em <http://nccanch.acf.hhs.gov>

Noguchi M S \& Assis SG 2003. Fonoaudiologia e violência intrafamiliar contra crianças: identificação de casos e prevenção. Pró-fono: Revista de Atualização Científica 15(2):199-206.

Secretaria Estadual de Saúde do Rio de Janeiro 2004. Dados epidemiológicos - Notificação de maus-tratos contra a criança e 0 adolescente. Disponível em <http:// www.saude.ri.gov.br>

Silva APBV \& M assi GA 1999. Práticas fonoaudiológicas: uma análise histórica. Pró-fono: Revista de Atualização Científica 11(1):150-152.

Silva KH 2001. A notificação de maus-tratos contra crianças e adolescentes pela Secretaria M unicipal de Saúde do Rio de Janeiro aos Conselhos Tutelares: em busca de uma parceria. Dissertação de mestrado. Instituto Fernandes Figueira-Fiocruz. Rio de Janeiro.

Sullivan PM , Brookhouser PE, Scanlan JM , Knutson JF \& Schulte LE 1991. Patterns of physical and sexual abuse of communicatively handicapped children. Annals of O tology, Rhinology, and Laryngology 100(3): 188-194

Torres WC \& GuedesWG 1987. 0 psicólogo e a terminalidade. Arquivo Brasileiro de Psicologia, 39(2):29-38.

Artigo apresentado em 5/5/2004

Aprovado em 13/7/2004

Versão final apresentada em 16/7/2004 